\title{
Canadian Institutes of Health Research funding of prison health research: a descriptive study
}

\author{
Fiona G. Kouyoumdjian MD PhD, Kathryn E. McIsaac MSc PhD, Jessica E. Foran MA, \\ Flora I. Matheson PhD
}

\section{Abstract}

Background: Health research provides a means to define health status and to identify ways to improve health. Our objective was to define the proportion of grants and funding from the Government of Canada's health research investment agency, the Canadian Institutes of Health Research (ClHR), that was awarded for prison health research, and to describe the characteristics of funded grants.

Methods: In this descriptive study, we defined prison health research as research on the health and health care of people in prisons and at the time of their release. We searched the CIHR Funding Decisions Database by subject and by investigator name for funded grants for prison health research in Canada in all competitions between 2010 and 2014. We calculated the proportion of grants and funding awarded for prison health research, and described the characteristics of funded grants.

Results: During the 5-year study period, 21 grants were awarded that included a focus on prison health research, for a total of $\$ 2289$ 948. Six of these grants were operating grants and 6 supported graduate or fellowship training. In total, $0.13 \%$ of all grants and $0.05 \%$ of all funding was for prison health research.

Interpretation: A relatively small proportion of CIHR grants and funding were awarded for prison health research between 2010 and 2014. If prison health is a priority for Canada, strategic initiatives that include funding opportunities could be developed to support prison health research in Canada.

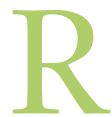
esearch is instrumental to understanding and improving the health of individuals and populations. Article 15 of the International Covenant of Economic, Social and Cultural Rights, which was ratified by Canada in 1976, identifies the right of all people " $[\mathrm{t}] \mathrm{o}$ enjoy the benefits of scientific progress and its applications." However, health research may not include certain populations and its benefits may not reach some populations, with potentially substantial consequences to individual and population health.

In Canada, about 40000 people are in correctional facilities on any given day, ${ }^{1}$ and about 1 in 250 adults spend time in a correctional facility in Canada each year. ${ }^{2}$ Research from Canada and other countries shows that the health of people who experience incarceration is substantially worse than the health of the general population with respect to social determinants of health, mental illness, substance use, mortality, communicable diseases, and intentional and unintentional injuries..$^{3-5}$ There is growing evidence for strategies to improve the health of this population while in custody and after release to the community, ${ }^{6}$ although many of these interventions have not been implemented in Canada. Improving the health of this population could reduce health inequity, contribute to public health through lower transmission of communicable diseases, improve public safety through the treatment of substance use disorders and mental illness, and lower costs of reincarceration and inappropriate health care use.?

There is a lack of health research in Canada that is focused on people who experience incarceration, and a particular paucity of interventions research. ${ }^{6,8} \mathrm{~A}$ recent study in the United States found that National Institutes of Health funding for criminal justice health research was small, and the authors suggested that greater focus and investment by the US federal government on criminal justice health research could transform health care and improve health for this population. ${ }^{9}$ Because the Canadian Institutes of Health Research (CIHR) is the Government of Canada's "health research investment agency" 10 and its mission is to create new scientific knowledge and to enable the translation of that knowledge into improved

Competing interests: None declared.

This article has been peer reviewed.

Correspondence to: Fiona Kouyoumdjian, kouyoumdjiaf@smh.ca CMAJ Open 2017. DOI:10.9778/cmajo.20160064 
health, more effective health services and products, and a strengthened health care system for Canadians, ${ }^{11}$ the CIHR could similarly play a key role in improving the health of this population through support of prison health research in Canada, including through direct funding.

Our objective was to define the proportion of CIHR grants and funding between 2010 and 2014 that was awarded for research focused on prison health, and to describe the characteristics of funded grants.

\section{Methods}

\section{Search}

We developed a search strategy in consultation with an information specialist to examine grants funded in competitions between January 2010 and December 2014. We chose this period to reflect the recent funding context, to include several years and because 2014 was the most recent year for which complete decisions data were available. To define the total number of grants awarded and the total amount of funding during this period, we searched the CIHR Funding Decisions database for all grants funded by CIHR.

We used 2 strategies to identify grants for prison health research in competitions between 2010 and 2014 in the CIHR Funding Decisions database: a search using subject terms and a search using investigator names. For the search using subject terms, we defined the terms through an iterative process, in which we reviewed relevant abstracts to identify various terms used to describe the population of interest. Our final subject terms were any of the following: prison, imprisonment, jail, detention, incarcerated, incarceration, offender, probation, parole, correctional, convict, inmate, criminal, crime, corrections, détenu, incarcéré, carcéral, but not the term "troubles de la parole," which is a French term for speech disorders.

We conducted a search using the names of investigators who publish in the field of prison health research, to improve the sensitivity of the search. We developed a list of names of investigators by conducting a search in PubMed (on Feb. 17, 2016) for prison health research published in 2015, assuming that investigators who received CIHR funding for prison health would likely be publishing research in this field after their grant was funded. We used the following search terms in PubMed: ([prison* OR imprison* OR jail* OR detention OR incarcer* OR offender* OR probation OR parole OR correctional system OR convict* OR inmate* OR criminal* OR crime*] AND Canada) AND ("2015/1"[Date - Publication]: "2015/12"[Date - Publication]). We assessed the records identified in this search as per our review procedures (detailed subsequently), and compiled a list of the names of first and last authors of prison health research publications. We then searched the CIHR Funding Decisions database with the name of each investigator without specifying subject terms.

\section{Inclusion criteria}

We defined 2 inclusion criteria: an explicit focus on the health and health care of people in prisons (i.e., people who were detained or incarcerated in Canada whether in a federal, pro- vincial or territorial correctional facility, or who had been released from custody within the past year), and a focus on health as defined by the Canadian Institute for Health Information, ${ }^{12}$ which includes indicators of health status, determinants of health and health system performance. In this paper, we use the summary term "prison health research" to describe PubMed records and grants that meet these 2 criteria.

\section{Review procedures}

For the results of the PubMed search to identify investigators conducting prison health research, 2 authors (FK and KM) reviewed the titles and abstracts to determine if the records met the inclusion criteria. If either reviewer thought that the record was relevant, the investigators' names were used in the CIHR Funding Decisions database search.

One author (FK) ran the searches in the CIHR Funding Decisions database using the subject terms and using each investigator name. After eliminating duplicates, 2 authors (FK and $\mathrm{KM}$ ) reviewed all grants to determine whether they met the inclusion criteria. For grants with no abstract in the database, we contacted the lead investigator to request further information such as an abstract or summary, and in 1 case decided on eligibility based on the title. Any disagreements regarding relevance were resolved through discussion. For grants that did not meet the inclusion criteria, the authors categorized the reason why the grant was not eligible. For grants that did meet the inclusion criteria, the reviewers extracted data on the CIHR institute that funded the grant and categorized the subject focus of the grant (e.g., mental health, infectious diseases). We also identified grants that included an explicit focus on prison health research, but which also had a focus on other populations or settings - for example, a grant for research focused on people who were incarcerated as well as on other people who were involved in the criminal justice system but not incarcerated. We assumed that at least a proportion of each of these grants would be targeted toward prison health research.

\section{Results}

The PubMed search to identify investigators who conducted prison health research yielded 308 records. Of these, 25 records met the inclusion criteria, from which we identified 44 unique investigators. As shown in Figure 1, the search by investigator name in the CIHR Funding Decisions database identified 52 funded grants in total and 50 unique grants. The search by subject in the CIHR Funding Decisions database identified 133 funded grants, 9 of which were also identified in the investigator search. In total, there were 174 unique grants identified in the subject and investigator searches.

Of the 133 grants identified in the subject search, $112 \mathrm{did}$ not meet the inclusion criteria for the following reasons: 48 noted that incarceration or other criminal justice involvement was prevalent or associated with the population or condition under study (e.g., disease or social determinant) but did not focus on prison health research, 16 focused on people in contact with the criminal justice system but not clearly 


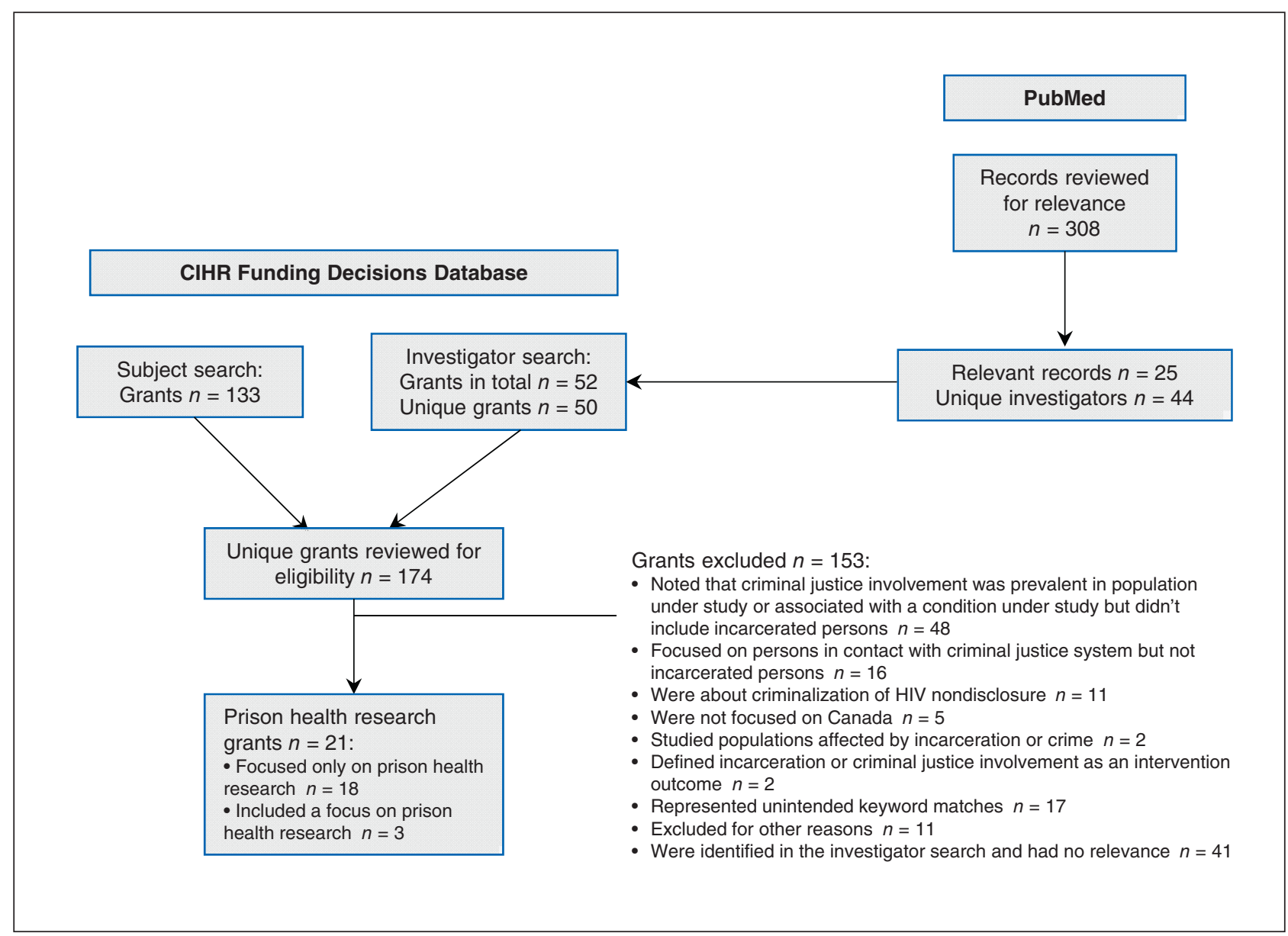

Figure 1: Flow diagram of search for Canadian Institutes of Health Research grants for prison health research, $2010-2014$.

people who experienced incarceration, 11 were about the criminalization of HIV nondisclosure, 5 were not focused on Canada, 2 were for studies involving populations affected by incarceration or crime such as children of incarcerated women or survivors of sexual assault, 2 intended to measure the impact of an intervention on incarceration or criminal justice involvement, 17 had unintended keyword matches such as "correctional surgery" or "conviction" about an idea, and $11 \mathrm{did}$ not meet the inclusion criteria for other reasons. The search using investigator names did not identify any additional relevant grants.

We identified 18 grants for prison health research, and the total funding for these grants was \$2 127948 . Three other grants included an explicit focus on prison health research in addition to a focus on other populations or settings. Thus, 21 grants focused on prison health research, representing \$2 289948 of funding. In all competitions between 2010 and 2014, CIHR funded 16336 grants for a total of \$4 520974400. Therefore, $0.13 \%$ of all grants and $0.05 \%$ of all funding was spent on prison health research.

Table 1 shows the characteristics of the 21 grants that included a focus on prison health research. Six operating grants were funded in prison health research during the 5 -year study period. Most grants had a disease-specific focus, such as mental illness or blood borne infections, and a small number of grants had a broader focus, such as health status or health care. The Institute for Population and Public Health funded the largest number of grants $(n=7)$ and the Institute of Human Development, Child and Youth Health provided the largest amount of funding (\$698 011).

\section{Interpretation}

For every 100 dollars of funding from CIHR, less than 5 cents were spent on prison health research between 2010 and 2014. About 1 in every 1000 grants was for prison health research, and the total funding per year for prison health research was less than $\$ 500000$ during this period.

What amount of CIHR funding would be appropriate for prison health research and how should this be decided? A recent US study identified a similarly low level of funding for criminal justice health research, at less than $0.1 \%$ of all grants funded by the National Institutes of Health between 2008 and 2012, and $0.1 \%$ of all funding awarded in 2012. ${ }^{9}$ Although it is difficult to define an appropriate level of funding for research on any population or disease, there should be transparent strategies in place to systematically identify and support areas of research that are important for Canada; ${ }^{13,14}$ for 


\begin{tabular}{|c|c|c|}
\hline Characteristic & $\begin{array}{l}\text { No. (\%) of } \\
\text { grants }\end{array}$ & Funding, \$ \\
\hline \multicolumn{3}{|l|}{ Grant type } \\
\hline Operating & $6(28.6)$ & 1237944 \\
\hline $\begin{array}{l}\text { Planning or knowledge } \\
\text { dissemination }\end{array}$ & $6(28.6)$ & 215659 \\
\hline Catalyst & $3(14.3)$ & 98845 \\
\hline $\begin{array}{l}\text { Graduate or fellowship training } \\
\text { funding }\end{array}$ & $6(28.6)$ & 647500 \\
\hline \multicolumn{3}{|l|}{ Subject } \\
\hline Mental health & $8(38.1)$ & 1596611 \\
\hline Blood borne infections & $3(14.3)$ & 85520 \\
\hline Health status & $3(14.3)$ & 149171 \\
\hline Social determinants of health & $2(9.5)$ & 55313 \\
\hline Health care & $2(9.5)$ & 39336 \\
\hline Self-harm & $1(4.8)$ & 105000 \\
\hline Substance use & $1(4.8)$ & 93997 \\
\hline Mortality & $1(4.8)$ & 165000 \\
\hline \multicolumn{3}{|l|}{ CIHR Institute } \\
\hline Population and Public Health & 7 (33.3) & 447698 \\
\hline $\begin{array}{l}\text { Health Sciences and Policy } \\
\text { Research }\end{array}$ & $3(14.3)$ & 344582 \\
\hline Aboriginal Peoples' Health & $2(9.5)$ & 55313 \\
\hline $\begin{array}{l}\text { Human Development, Child and } \\
\text { Youth Health }\end{array}$ & $2(9.5)$ & 698011 \\
\hline Infection and Immunity & $2(9.5)$ & 65845 \\
\hline $\begin{array}{l}\text { Neurosciences, Mental Health } \\
\text { and Addiction }\end{array}$ & $2(9.5)$ & 449018 \\
\hline Gender and Health & $1(4.8)$ & 105000 \\
\hline
\end{tabular}

example, in consideration of the size of the affected populations, the burden of disease, potential impact on important outcomes, equity and the political and legal context. ${ }^{15}$ If prison health research is a priority for Canada on the basis of these or other criteria, we should identify and implement pull and push mechanisms to support this focus, ${ }^{16}$ including targeted funding opportunities, training, early or mid-career awards, prizes for research and ways to facilitate research in correctional facilities. Defining such strategies should include people who are involved in advocacy and research focused on prison health, including people with a history of incarceration, consistent with CIHR's Framework for Citizen Engagement and Strategic Plan. ${ }^{14,17}$

In addition to the issue of funding, advancing prison health research requires examining and addressing the unique challenges and constraints of conducting research in correctional settings and with vulnerable populations. ${ }^{6} 18$ Ethical issues, such as obtaining voluntary consent, privacy and not causing harm are challenging; ${ }^{19,20}$ in contrast with the US, ${ }^{19}$ we lack specific Canadian guidance on contemporary research issues with this population and in this setting. ${ }^{21}$ Institutional barriers include the need for and costs of security staff to supervise research activities, and research may not fit within the mandate of correctional authorities. It may be difficult to follow research participants through transfers and at the time of release from custody. Finally, access issues pose challenges to including people who are incarcerated in research development and implementation, although this has been achieved by at least 1 group of researchers in Canada. ${ }^{22}$

\section{Limitations}

We conducted a PubMed search to improve the sensitivity of our search for funded CIHR grants, but because it typically takes years between the time that funding is awarded and study results are published, a search of papers published in 2015 would likely not include publications from studies that were funded in the latter part of the study period. We defined the study period as 2010 to 2014 because 2014 was the most recent year for which all CIHR funding decisions were available at the time of the search, and we wanted to focus on the current funding context; however, we assumed that most people who were awarded CIHR funding would be publishing in this field before and after being awarded funding and would therefore be identified in the search.

Information on all submitted grants is not publicly available, so we do not know whether the low level of funding reflects a lack of submitted proposals on prison health research. We considered funding from CIHR as an indicator of federal government support for prison health research; however, there are other avenues for the federal government to financially support prison health research, such as indirect support through funding the Correctional Service of Canada. In addition, there could be direct support for prison health research from the Social Sciences and Humanities Research Council, although this is unlikely during the period under examination because the eligibility criteria for the Social Sciences and Humanities Research Council changed to exclude health research in 2009.23 The federal government may also contribute to knowledge generation through routine operations such as surveillance, as opposed to formal research.

Research focused on other populations and other settings may have relevance to people in correctional facilities, including subpopulations that are disproportionately represented in correctional facilities, such as people who use drugs and Indigenous people. ${ }^{3,4}$ However, important differences in context and in the legal status of people in prisons and post-release may limit the generalizability of other research to this population and setting.

\section{Conclusion}

Between 2010 and 2014, a relatively small proportion of CIHR grants and funding were awarded for prison health research. A large number of people in Canada experience incarceration, and this population tends to have poor health compared with the general population. Improving the health 
of prisoners could contribute to improving health equity and population health, and health research may be instrumental to improving health. If improving prison health is a priority in Canada, explicit attention should be paid to opportunities to support prison health research, including through CIHR funding.

\section{References}

1. Walmsley R. World prison population list. 10th ed. London (UK): King's College London International Centre for Prison Studies; 2013.

2. Kouyoumdjian FG, McIsaac KE. Persons in correctional facilities in Canada: A key population for hepatitis $\mathrm{C}$ prevention and control. Can 7 Public Health 2015;106:e454-6

3. Fazel S, Baillargeon J. The health of prisoners. Lancet 2011;377:956-65.

4. Kouyoumdjian F, Schuler A, Hwang SW, et al. The health status of prisoners in Canada: a narrative review. Can Fam Physician 2016;62:215-22.

5. Kouyoumdjian FG, Kiefer L, Wobeser W, et al. High mortality over 12 years of follow up in people admitted to provincial custody in Ontario: a retrospective cohort study. CMA7 Open 2016;4:E153-61.

6. Kouyoumdjian FG, McIsaac KE, Liauw J, et al. A systematic review of randomized controlled trials of interventions to improve the health of persons during imprisonment and in the year after release. Am 7 Public Health 2015; 105:e13-33.

7. Kinner SA, Wang EA. The case for improving the health of ex-prisoners. Am 7 Public Health 2014;104:1352-5.

8. Kouyoumdjian FG, Schuler A, Hwang SW, et al. Research on the health of people who experience detention or incarceration in Canada: a scoping review. BMC Public Health 2015;15:419.

9. Ahalt C, Bolano M, Wang EA, et al. The state of research funding from the National Institutes of Health for criminal justice health research. Ann Intern Med 2015; 162:345-52.

10. About us. Ottawa: Canadian Institutes of Health Research; 2016. Available: www.cihr-irsc.gc.ca/e/37792.html (accessed 2016 Mar. 20)

11. Our mandate. Ottawa: Canadian Institutes of Health Research; 2013. Available: www.cihr-irsc.gc.ca/e/7263.html (accessed 2016 Mar. 9).

12. Health indicators 2012. Ottawa: Canadian Institute for Health Information; 2012. Available: https://secure.cihi.ca/free_products/health_indicators_2012 en.pdf (accessed 2016 Feb. 10).

13. Chalmers I, Bracken MB, Djulbegovic B, et al. How to increase value and reduce waste when research priorities are set. Lancet 2014;383:156-65.

14. Health Research Roadmap II: capturing innovation to produce better health and health care for Canadians: Strategic Plan 2014-15-2018-19. Ottawa: Canadian Institutes of Health Research; 2015. Available: www.cihr-irsc.gc. ca/e/48964.html (accessed 2016 Apr. 26).
15. Erickson LJ, De Wals P, Farand L. An analytical framework for immunization programs in Canada. Vaccine 2005;23:2470-6.

16. Mueller-Langer F. Neglected infectious diseases: are push and pull incentive mechanisms suitable for promoting drug development research? Health Econ Policy Law 2013;8:185-208

17. Citizen engagement. Ottawa: Canadian Institutes of Health Research; 2012 Available: www.cihr-irsc.gc.ca/e/41592.html (accessed 2016 Apr. 26).

18. Quina K, Garis AV, Stevenson J, et al. Through the bullet-proof glass: conducting research in prison settings. 7 Trauma Dissociation 2007;8:123-39.

19. Gostin L. Ethical considerations for research involving prisoners. Washington (DC): Institute of Medicine; 2007.

20. Levine RJ. Ethics and regulation of clinical research. 2nd ed. New Haven (CT): Yale University Press; 1988.

21. Tri-council policy statement: ethical conduct for research involving humans. Ottawa: Canadian Institutes of Health Research, Natural Sciences and Engineering Research Council of Canada, Social Sciences and Humanities Research Council of Canada; 2010. Available: www.pre.ethics.gc.ca/pdf/eng/tcps2/ TCPS_2_FINAL_Web.pdf (accessed 2016 Mar. 1)

22. Elwood Martin R, Murphy K, Hanson D, et al. The development of participatory health research among incarcerated women in a Canadian prison. Int 7 Prison Health 2009;5:95-107.

23. Subject matter eligibility. Ottawa: Social Sciences and Humanities Research Council; 2014. Available: www.sshrc-crsh.gc.ca/funding-financement/applydemande/background-renseignements/selecting_agency-choisir_organisme _subventionnaire-eng.aspx (accessed 2016 Mar. 20).

Affiliations: Centre for Urban Health Solutions (Kouyoumdjian, Matheson), St. Michael's Hospital, Toronto, Ont.; Research Services (McIsaac), Nova Scotia Health Authority, Halifax, NS; Department of Political Science (Foran) and Department of Family Medicine (Kouyoumdjian), McMaster University, Hamilton, Ont.

Contributors: Fiona Kouyoumdjian and Kathryn McIsaac acquired data and conducted analyses. Fiona Kouyoumdjian drafted the manuscript. All of the authors contributed to study conception, design, and interpretation, revised the article, approved the final version to be published and agreed to act as guarantors of the results.

Funding: Fiona Kouyoumdjian received salary support from a Canadian Institutes of Health Research Fellowship.

Acknowledgement: The authors thank Carolyn Ziegler for her contributions to the development of the search strategy.

Supplemental information: For reviewer comments and the original submission of this manuscript, please see www.cmajopen.ca/content/5/1/ E14/suppl/DC1 